\title{
9. REVIEWING THE FIELD OF TECHNOLOGY EDUCATION IN NEW ZEALAND
}

\section{INTRODUCTION}

In this chapter we discuss the development of technology as a field of study within compulsory education in New Zealand. We argue that technology education has found a place in the national curriculum, research, and teacher education, resulting in technology classroom practice to some degree in all New Zealand schools.

We report first on curriculum developments in terms of the shift from technical subjects to the initial technology curriculum (Ministry of Education, 1995), and on to the development of the second technology curriculum released in 2007 (Ministry of Education, 2007). An overview is also presented of the research undertaken to inform and evaluate curriculum development and implementation, followed by a discussion of research in technology education undertaken to inform teaching and learning generally. The chapter moves on to discuss the history of technology teacher education through professional development support. Implementation of the 1995 technology curriculum was initially supported with significant in-service teacher professional development, and pre-service technology teacher education programmes were in place by 1998 . However, little ongoing support was provided for this group. We suggest that the resultant teacher education has been varied and variable, although a number of initiatives are seeking to address this. Finally, we discuss issues and challenges for technology education in the future, and briefly outline planned developments that may begin to address these.

\section{FROM TECHNICAL TO TECHNOLOGICAL}

New Zealand has a long history of technical education in the senior primary and secondary school (Burns, 1992). A national school system was established in New Zealand in 1877, and in 1890 technical education was introduced. Technical education was strongly skills-based and reflected the social perspective of the time, particularly regarding what was gender appropriate: metal and woodwork for boys; cooking, needlework, and/or laundry for girls. In 1900 the new Manual and Technical Instruction Act was passed into law (New Zealand Statutes, 1900) and secondary schools were required to extend their traditional academic curriculum to incorporate technical subjects. However, parents were generally reluctant to enrol their children in these subjects due to their being "stamped with the label of social inferiority" (McKenzie, Lee, \& Lee, 1990, p. 4) and, as such, limiting their child to later employment as low-paid, unskilled, or manual workers. Soon after this, technical high schools were developed. Despite Government intentions, these schools focused on vocationally-oriented, skill-based programmes that served to channel working class children into manual and trade employment and reinforce the divide between 'white' and 'blue' collar workers in New Zealand. 
By the mid 1920s, education advocates were calling for the leaving age of secondary school students to be raised from 12 to 15 years and for the abolishment of technical schools. In their place, comprehensive post-primary schools were promoted that offered a 'multi-lateral' curriculum (Compton, 2001). These schools were to provide all students with a $60 \%$ common content-based programme, with the remaining time being divided into two areas of semi-specialisation; either 'academic' or 'non-academic'. Technical education was sited in specialist wood and metal workshops and homecraft (food and textiles) rooms and the classroom curricula placed importance on the creation of products with high 'take home value'. The pedagogical practices of technical teachers centred on the 'lock-stepped' construction of products in accordance with teacher predetermined plans in woodwork and metalwork, patterns in textiles, and recipes in cooking. This approach was embedded in behaviourist theories of learning in order to support students to attain the 'desired competencies' (Harwood \& Compton, 2007).

Manual-technical training was criticised at the time as: “... the most glaring instances of rigid formalism ... that quite overlooked the creative impulses of children ... it certainly implanted sterile conceptions of art and handwork (Campbell, 1941, pp. 94-95). Despite these criticisms, teachers of woodwork and metalwork were not encouraged to change their behaviourist pedagogical practices until 1975, when Workshop Craft was introduced and mandated as the curriculum for technical education for hard materials (woodwork and metalwork) for Year 7-10 students. The homecraft curricula for home economics and clothing and textiles did not follow the hard material lead, however, and continued to endorse behaviourist practices (Harwood \& Compton, 2007).

During the 1980s there were further moves to disrupt the purely skills-focused programmes and behaviourist approaches of technical education through the promotion of a stronger design focus and the use of a wider range of materials. This saw the emergence of such subjects as Workshop Technology and Graphics and Design. During this time there were also attempts to break down the gender-stereotyped nature of technical education by having girls and boys taking all technical/technology subjects in senior primary and junior high school. However, at senior high school these subjects still tended to be very gender specific. During this time there was also an increasing emphasis on 'technology' in existing school subjects. For example, science teachers were including a 'technology as applied science' aspect, social studies teachers were beginning to focus on technology as a 'determining' social force, and information technology teachers were focusing on understanding technology as hardware - primarily computers.

All of the above signalled a shift from technical education to a more technological education. However, the remnants of past technical curricula initiatives and teaching approaches resulted in a limited range of skills, processes and knowledge from a narrow and often gendered perspective. As a consequence, students right through to the early 1990s had little opportunity in New Zealand for broad and coherent experiences in technology that were considered conducive to developing citizens who could contribute successfully in a contemporary society.

\section{TECHNOLOGY - A LEARNING AREA IN ITS OWN RIGHT}

Technology as a separate subject area emerged as a key outcome from the 1990 curriculum reforms, which in turn were influenced by earlier curriculum reviews undertaken in the 1980s, including a 1984 review of the curriculum for schools (Department of Education, 1987). The public discussion and consultation was substantial - 21,500 submissions initially, with 10,000 submissions to the draft report from a total population of approximately 3.4 million. The resulting recommendation was that there be a national common curriculum for all schools, from new entrants to Form 5 (Years 1-10), and that it include national curriculum principles as well as knowledge, skills, attitudes, and values. In 1990, a new government embarked on a project to 
revise the curriculum in primary and secondary schools under the banner of The Achievement Initiative (Ministry of Education, 1991). Many of these ideas were influenced by the curriculum reforms taking place in England and Wales at the time. The policies emphasised raising standards, developing levels of attainment, the notion of progression linked to accountability, and the contracting out of the curriculum development process (Bell, Jones, \& Carr, 1995). As part of an educational review process, a Ministerial Task Group was set up jointly by the Minister of Education and the Minister of Research, Science and Technology in June 1991 to review science and technology education. Some of the recommendations from the task group concerning technology education were that: a technology curriculum be developed as an area in its own right; there be adequate teacher training and resourcing for technology education; technology curricula should not be imported from overseas; and the inclusiveness of technology education be emphasised, including Maori ${ }^{1}$ input and the use of Maori language (Ministry of Research, Science and Technology, 1992). This report was endorsed by members of the business community and by two Ministers of the Crown.

In 1992, the Ministry of Education contracted the Centre for Science and Mathematics Education Research (CSMER) at the University of Waikato to develop a policy framework for technology education in New Zealand. The contract required that: there be wide consultation; best practice be taken into account, nationally and internationally; it be consistent with other government policies in education; it take account of resources, teacher change, teacher development, qualifications frameworks, etc.; and it where possible provides a range of options. The development of the policy thus had to fit within the structure of the New Zealand Curriculum Framework (Ministry of Education, 1993) in terms of levels, strands, achievement aims, and objectives.

The policy decided the general aims of the technology curriculum, the technological areas, classroom and implementation directions, as well as approaches to teaching, including initial assessment ideas. This policy work drew extensively from the Learning in Technology Education (LITE) research project (Jones, Mather, \& Carr, 1995), in which ideas within the initial policy paper were explored with teachers and students in the primary and secondary sector prior to the development of the draft technology curriculum. The LITE research also analysed teacher interview data captured during technology unit planning and delivery, providing insights into teacher understandings of the philosophical and theoretical base of technology education. In addition, extensive student data was gathered before, during, and after technological experiences and analysed in terms of technological practice as well as broader concepts of technology and technology education (Mather, 1995).

The CSMER was then contracted to develop the first draft technology curriculum (Ministry of Education, 1993). The draft included three general aims, six strands with related achievement objectives, seven technological areas, and six contexts for learning. It also included a variety of suggested classroom activities under each strand. The draft curriculum statement was published for consultation in 1993 and trialled in schools during 1994. This provided teachers, tertiary educators, professional technologists, and members of the general public with an opportunity to respond to the ideas contained in the draft. In general, teachers and professional technologists were supportive of the underpinning structure and philosophy of the document. However, a reduction in the number of objectives and strands was recommended given the number of other curriculum documents teachers were working with. There was general consensus that the strands should reflect directly the three original aims of the technology curriculum: technological knowledge and understanding, technological capability, and technology and society. The reduction in strands from six to three did not change the underlying philosophy, but in fact strengthened the notion of technological practice as the conceptual base of the curriculum. These three strands would work together to support the new holistic overall single aim of technological literacy. Other contexts 
were added and the number of learning experiences was reduced but an attempt was made to make these more comprehensive and strand inter-related. The final Technology in the New Zealand Curriculum (Ministry of Education, 1995) thus included a single aim of developing student technological literacy through three learning strands of:

- Technological Knowledge and Understanding;

- Technological Capability; and

- Technology and Society.

These three interrelated strands provided a framework for teachers to develop coherent programmes of technology as part of a balanced curriculum.

The seven technological areas were: materials technology; information and communication technology; electronics and control technology; biotechnology; structures and mechanisms; process and production technology; and food technology. There were also nine contexts: personal life, the home, the school, recreation, the community, the environment, energy production and supply, business, and industry. Eight achievement objectives were developed for each of the three strands, and an attempt was made to write these across eight levels. Units of work were to be developed based on technological learning outcomes and reflective of achievement objectives from all three strands as well as one or more context and technological area (Ministry of Education, 1995). The dominant learning theories underpinning the 1995 technology curriculum were socio-cultural in nature with pedagogical approaches seeking to embed student learning in authentic and empowering contexts. While published in 1995, the curriculum was not mandated for full implementation until 1999. Implementation was supported in various and variable ways, discussed later in the chapter.

\section{TIME TO TAKE STOCK}

In 2001 a national curriculum stocktake was undertaken in New Zealand that included reviews of learning area curricula, international evaluations, and analysis of teachers' experiences of the curricula in practice. This stocktake was accomplished through the National School Sampling Study (NSSS). Along with other learning areas, the NSSS provided an opportunity for teachers who had been involved in implementing technology in the New Zealand curriculum to share their experiences (Jones, Harlow, \& Cowie, 2004). Key aspects that were investigated included: background and experience of teachers; general issues related to implementation; practice; professional support; the curriculum documents; and impact and compliance issues. The NSSS sought teacher feedback through national focus groups, questionnaires and case studies.

Findings from the study were reasonably positive in relation to teachers' experiences in the implementation of the technology curriculum in New Zealand schools from Years 1-13. However, there were variations between teachers in different kinds of schools and within school types, especially between primary and secondary school teachers. There was a general degree of satisfaction with the curriculum statement, although one third of teachers (33\%) wanted to make changes. The most common change was to 'make it [the curriculum] more simple to understand' and to include 'more and better developed learning and assessment examples'. The 1995 technology curriculum statement was reported as having been most helpful for planning, gaining an overview of the progression of key technological ideas, achieving consistent understanding of the curriculum levels, and assessing student achievement. However, half of all teachers reported that they only 'sometimes' found the curriculum statement helpful for gaining an overview of the progression of key ideas.

Although $70 \%$ of teachers reported in the questionnaires that the curriculum statement was 'always' or 'sometimes' helpful in assessing achievement, many also reported difficulties with 
assessment in technology. The most popular approach to assessing student learning in technology was the use of 'practical tasks'. Large classes, the 'time' factor, and establishing level accuracy were also issues, but these were only noted by less than $20 \%$. Secondary school teachers were more concerned with the amount of paperwork required than teachers in other sectors. They were also influenced by the perception of qualification requirements. At the primary level, teachers were concerned about finding appropriate forms of assessment for the junior years and felt that they needed more guidance, both in planning and in assessment.

Nearly three-quarters of the teachers $(73 \%)$ reported receiving some form of professional development in technology. For almost $50 \%$ of respondents, 'other teachers in the school' had been the most useful source of knowledge. For $75 \%$, professional development had been helpful, and $28 \%$ found it had given them sufficient depth of knowledge to plan and implement the technology curriculum as well as helping them to gain confidence in teaching technology. However, across all school types, two thirds of the teachers expressed a medium level of confidence in teaching technology and only one-fifth a high level of confidence. Teachers were most interested in receiving future professional development in the specific technological areas. Information on planning and teaching skills was requested and respondents were also interested in knowing more about progression, assessment, and reporting of student achievement.

According to $88 \%$ of teachers, all students up to and including Year 10 studied technology in their respective schools. The majority of teachers considered that technology should be compulsory for all students to the end of Year 10 as it provided students with important skills. Over $60 \%$ of schools were integrating technology with other learning areas. This was particularly evident in primary schools $(71 \%)$. Most of these teachers tended to integrate technology into languages and/or science. Secondary school technology teachers taught technology in blocks or modules or as a new subject with its own timetable slot.

Teachers detailed a wide range of approaches that had been successful in their teaching of technology. These included: choosing topics of relevance to students; practical, hands-on learning activities; a 'problem-solving approach'; and group or co-operative learning approaches. Teachers tended to favour a student-centred approach to teaching technology. Fifty-three percent of secondary school (Year 9-12) teachers placed greater emphasis on technological capability than the other strands. Concerns about the level of student knowledge and skills needed to cope with curriculum requirements were expressed by $31 \%$ of secondary school teachers.

Materials technology and food technology were reported to be the most widely-taught technological areas in New Zealand schools. However, all technological areas were reported as being taught in primary schools to some degree, with biotechnology the least common. Fewer teachers in intermediate/middle schools taught food technology or electronics and control technology - perhaps because specialist technology teachers often covered these areas. Overall it appeared that apart from the more traditional technical-related technological areas of food and materials technology, secondary school schools had not developed courses in other technological areas to the same extent as in primary schools. In keeping with the findings from the primary sector, biotechnology was the least common area taught.

In response to a question regarding the major challenges faced in implementing the technology curriculum, the prime concern of teachers was the difficulty of resourcing the necessary equipment ( $50 \%$ overall; $60 \%$ of primary teachers). Although many secondary school teachers had new facilities in which to work, they still reported difficulties establishing technology in their schools because of timetable constraints, management decisions, or lack of enthusiasm on the part of former home economics and wood/metal teachers. Secondary school teachers were also grappling with the introduction of new national qualification requirements, although in many cases the technology achievement standards provided additional guidance and incentive for implementing 
technology in junior secondary programmes. What was termed a 'crowded curriculum' was found to be a major challenge for $32 \%$ of all respondents, particularly in the primary sector. As teachers who teach all areas of the national curriculum, primary teachers reported overcoming this to a certain extent by integrating technology with other subject areas. Understanding the 1995 technology curriculum statement was listed as one of the major challenges by almost a quarter of the respondents.

\section{TECHNOLOGY REFINED AND REDEVELOPED}

Results in technology achievement standards and findings from national research projects, including the National Education Monitoring Project (NEMP), indicated that school-based technological practice was leading to: high levels of student engagement; increasing levels of ownership of learning; increasing levels of empowerment resulting in an enhanced ability to make decisions; and effective collaboration with others to make a difference to their own lives and developments in their immediate community (e.g., Compton \& Harwood 2003; Jones \& Moreland, 2003). However, teachers reported and technology achievement standard results showed that student technological literacy was often limited in breadth and depth of knowledge, and lacking in the level of critical analysis required for more informed decision making.

Further policy work was therefore undertaken in 2004 as part of a review of the national curriculum, known as the New Zealand Curriculum Marautanga Project (NZCMP). This work sought to provide a stronger focus on the philosophical basis of technology and technological knowledge (Compton, 2004; Compton \& Jones, 2004). Based on research and new policy thinking, it was decided to restructure technology around three new strands - technological practice, technological knowledge, and the nature of technology. These strands were still seen as working together to realise the aim of developing student technological literacy, but the nature of this literacy was reconceptualised to be broader, deeper and more critical (Compton \& France, 2007a).

The concept of technological practice was considered to be well defined from understandings gained from classroom-based research carried out in New Zealand over the last ten years. Key constructs such as the 'components of [technological] practice', and supporting 'indicators of progression' within them, had also been developed, trialled, and validated within New Zealand classrooms (Compton \& Harwood, 2004, 2005) and were available for development into levelled achievement objectives.

The Technological Knowledge and Nature of Technology (TKNoT) research project sought to establish the key components of the remaining two strands - technological knowledge and the nature of technology. A central part of the technological knowledge focus was to work with key technology networks representing all significant technological sectors within New Zealand, including leading academic and/or industry biotechnologists, engineers, food technologists, control technologists, information and communication technologists, architects, product developers, and designers (Compton \& France, 2007b). While these participants also discussed aspects of the nature of technology, international experts involved in the philosophy of technology provided considerable input into the philosophical underpinnings of the nature of technology focus (Compton \& France, 2007b). This access to international experts allowed discussion of developing ideas outside of the New Zealand context. Notions of technological knowledge and the nature of technology were also explored with teachers and students (Compton \& France, 2007c). As a result of the TKNoT research, two components were established within the nature of technology strand and three components within the technological knowledge strand (see Table 1).

This framework provided a more robust philosophical and theoretical base for ongoing curriculum development work, and addressed all concepts discussed by Mitcham (1994) as being focused on in technology education in varying ways. A draft of the introductory statement and a 
series of levelled achievement objectives for each of the identified components was prepared for consultation in 2006 and revised for release the following year in the New Zealand Curriculum (Ministry of Education, 2006, 2007). Socio-cultural and constructivist theories of learning provided an underpinning basis for learning, with pedagogical approaches seeking to embed student learning in authentic and empowering contexts and provide students with established understandings and practices from which to undertake more informed practice and make more critically reflective decisions.

Table 1. Redeveloped technology strands (Compton \& France, 2007a, p. 268).

\begin{tabular}{lll}
\hline Technological practice & Technological knowledge & Nature of technology \\
\hline - Brief development & - Technological modelling & - Characteristics of \\
- Planning for practice & - Technological products & technology \\
- Outcome development & - Technological systems & - Characteristics of \\
and evaluation & & technological outcomes \\
\hline
\end{tabular}

\section{RESEARCH INTO TEACHING AND LEARNING}

Technology education research in New Zealand has increased significantly over the last two decades. Early work in the 1980 s, tended to focus on using technology to enhance the learning of science, such as using technological applications to teach science (e.g., Jones \& Kirk, 1990). Policy moves to include a broad notion of technology in the curriculum in the late 1980s and early 1990s were associated with research commissioned by the Ministry of Education including research on student attitudes to technology based on the PATT questionnaires (Burns, 1992) and the Learning in Technology Education (LITE) project mentioned earlier.

Early LITE research focused on teachers' perceptions of technology and explored the influence of teachers' existing subcultures on the ways in which teacher might be prepared to implement the technology curriculum (Jones \& Carr, 1992). Classroom investigations explored ways in which students carried out technological activities; these were strongly influenced by classroom culture and student expectations (Jones, Mather, \& Carr, 1995; Mather, 1995). The final phase of the project explored effective characteristics of technology professional development for teachers (Compton \& Jones, 1998; Jones \& Compton, 1998).

From 1990 onwards there was an emergence of Masters and $\mathrm{PhD}$ research in the area of technology education as the area gained prominence in both schools and tertiary education, and a strong focus on teacher development was seen to coincide with full implementation of the 1995 curriculum. The targeting of resources for the professional development meant that there was no government-funded research during this time. Two national professional development programmes did, however, build on teacher development research (see below). They also included a research/evaluative component.

In 1998 there the focus of research shifted to assessment, with a strong emphasis on formative interactions to support 'assessment for learning'. Two projects were funded by the Ministry of Education in 1999 and 2000 to undertake research in this area: the Learning in Technology Education - Assessment (LITE-Assessment) project (Jones \& Moreland, 2003; Moreland, Jones, $\&$ Northover, 2001) and the Technology Education Assessment in Lower Secondary (TEALS) project, which was extended to the primary and senior secondary sectors in its second year (Compton \& Harwood, 2003, 2005). These projects shifted research back into New Zealand classrooms and resulted in moving understandings of teaching and learning forward. 
Classroom-based research from 1992-1997 (as reported by Jones, 1999) had shown that strategies developed by the teachers in their classrooms when implementing technological activities were often positioned within that particular teacher's teaching and subject sub-culture. For a new curriculum area such as technology, this presented particular challenges for teachers as they searched to construct a coherent content base in addition to pedagogical understandings, including appropriate assessment practices. More recent research in New Zealand has continued to focus on student and/or teacher concepts as evidenced by the increase in externally-contracted research and graduate research projects.

Technology is an activity that involves not just the social context, but also the physical context, with thinking being associated with and structured by the objects and tools of action. This means research in student learning has to consider not just conceptual and procedural understandings in isolation, but also the way technological tools and objects influence and interact with student thinking and doing. More research is required in this area to understand and support teacher pedagogical content knowledge for teaching in the technology classroom, particularly in keeping with the 2007 curriculum changes. To this end, the Technological Knowledge and Nature of Technology: Implications for Teaching and Learning (TKNoT:Imps) project, currently underway, seeks to explore the components of the two new strands of the reviewed technology curriculum in order to validate and further describe the nature of progression. A second project, Interactions in Science and Technology Education (InSiTE), is a longitudinal study focused on formative learning interactions (Cowie, Moreland, Jones, \& Otrel-Cass, 2008).

\section{THE VARIABLE STORIES OF TEACHER EDUCATION}

With the release of the 1993 draft technology curriculum, teacher education institutions began to grapple with the introduction of technology education and the implications for pre-service teacher programmes. Little coordinated professional development support was provided for personnel within these institutions, although pre-service teacher educators were often invited, along with inservice teachers educators, to Ministry of Education national meetings during 1995 and 1996. These meetings were, however, primarily to inform this group of current developments and Ministry of Education expectations. Technology Education New Zealand (TENZ) was established in 1995 in an effort to fill this gap and the biennial conference run since 1997 have provided a site for researchers, teacher educators, and teachers to meet and debate technology education issues.

During 1995-1997, the Ministry of Education funded a range of regional and national professional development programmes for in-service teachers in an attempt to support the implementation of technology. The regionally-based programmes were selected from proposals submitted in response to a Ministry of Education request for trial or pilot programmes. This resulted in a variety of programmes being accepted, the diversity of which is illustrated in the following examples of programme focus: biotechnology, technology links to English literacy, electronics and robotics, information and communication technology, and distance learning in technology. The majority of these programmes only ran during 1995 although in a few cases funding was extended until 1997. As a result, teachers in different regions experienced quite different professional development in technology and in some cases links to the 1995 technology curriculum were not a strong feature of the programme.

The two national programmes included the National Facilitator Training Programme and the Technology Teacher Development Resource Package (Compton \& Jones, 1998; Jones \& Compton, 1998). Both took into account past national and international research in teacher development as well as recent technology education baseline research carried out in New Zealand schools. They also included an evaluative research component. The National Facilitator Training 
Programme worked with a total of 30 participants from around New Zealand during 1995 and 1996. Participants included primary, intermediate and secondary teachers and teacher educators. Of the teacher educators, the majority were involved in in-service education although some also had preservice responsibilities. The aim of the programme was to ensure every region in New Zealand had at least one teacher education expert in technology to lead and inform subsequent regional and school-based professional development programmes. The Technology Teacher Development Resource Package was developed to provide teacher educators and all schools access to professional development support materials for use in school-based teacher development aligned to the 1995 technology curriculum. This package included industry/community technological practice videos, classroom practice videos, and written support material.

Both these programmes sought to ensure a consistency across the country. Unfortunately, the potential impact was never to be fully realised as the Ministry of Education decided in 1997 to cut further funding for technology professional development. Although the Technology Teacher Development Resource Package was sent to all schools, without facilitation support, it tended to sit pristine in its box in the school resource room. The trained facilitators returned to their previous positions or moved on in their careers. Many of them have since moved into in-service or preservice teacher education positions within tertiary institutions. By 1998 technology education formed a part of pre-service education for all students enrolled in primary teacher education programmes and was an option for suitably-qualified students in secondary teacher education programmes. However, differences in emphasis existed depending on the structure of the institution and the background of those employed to staff these programmes. In an attempt to address issues of inconsistency across regions, the Technology Education Assessment National Professional Development (TEANPD) project was funded by the Ministry of Education to ensure research findings from the TEALS and LITE-Assessment project were disseminated. This project involved teacher educators (both in-service and pre-service) as well as lead teachers in schools. In 2001, the Ministry of Education also funded limited resource development for Year 1-10 teachers through the Technology National Exemplar Project. An Exemplar Matrix for Technology Education developed as part of this project was controversial, however, as it neither reflected the 1995 technology curriculum, nor was in keeping with the LITE-Assessment or TEALS research findings. The matrix was abandoned in 2003 although a number of the exemplars were produced in an attempt to support more consistent understanding between teachers.

In 2004, a significant amount of funding was accessed from the Ministry of Economic Development to support technology education. This funding was managed by the Ministry of Education and was used to set up the Growth and Innovation Framework-Technology Initiative (GIF-Technology) (Dinning, 2007). Relatively stable funding with a ten-year lifespan (until 2013) has allowed the Initiative to be strategic on a level unprecedented in previous attempts to provide teacher professional development support for technology education in New Zealand. While funds were appropriated for the support of senior secondary students (Years $11-13$ ) work with students from Years $7-13$ was subsequently included on the basis that coherent programmes developed across this range would make gains in the senior secondary sector more likely. Major professional teacher education projects established to date include: resource and materials development and the development of Techlink, an online portal for technology educators and students; the Technology Beacon Practice Project to prepare case studies of exemplary classroom practice; a Technology Leader Support Programme including regional and national meetings for those responsible for translating the 2007 curriculum into appropriate school technology programmes; the 2007 Curriculum Support Package which provides an explanation of and guidance for the 2007 technology curriculum; and the establishment of a National Technology Professional Development Manager (NTPDM). ${ }^{2}$ A joint learning community of teacher educators, as well as separate in-service and 
pre-service teacher educator learning communities, established by the NTPDM, has resulted in a growing level of shared understandings and a collaborative and supportive network between regions and institutions.

The result of this more coherent support is beginning to result in strong regional programmes. In addition, a new purpose-developed graduate programme has been supported by the Ministry of Education at the University of Waikato. This programme recognises that the majority of teachers currently teaching technology trained without any formal technology education courses and seeks to redress this. Other graduate courses in technology are being developed and are aligned to the expertise of the provider. However, with greater alignment between different pre-service teacher educators, it is expected that these programmes will all serve to provide more consistent secondary technology teacher graduates. The Ministry of Education has also recently awarded 100 scholarships to support technology pre-service teacher education in the secondary sector. Of these, 59 are 'career changer' scholarships, meaning a significant influx of technologists entering the technology teaching fraternity.

\section{INTO THE FUTURE}

Technology education in New Zealand has never been stronger. After more than twenty years of research, trialling, and development we have established a robust curriculum framework, a growing body of researchers, and an increasingly collaborative network of technology teacher educators. Classroom practice in technology exhibited in many schools is of a high level. We have a qualification system with pathways into University, and technology scholarship results that reflect innovative and critical thinking and quality outcomes.

However, significant issues remain. In the secondary sector, teacher understandings of the 2007 technology curriculum and teacher supply remain two major challenges. Another significant issue is senior secondary qualifications. A new phase of development of Technology Achievement Standards is about to begin with the aim of ensuring that assessment tools align with the 2007 technology curriculum. Past experience has provided strong lessons as to the impact high-stakes assessment can have on programme design throughout the secondary sector. It is therefore critical that gains made in national curriculum development are not undermined by inadequate and/or inappropriate assessment tools and guidance within senior secondary programmes.

In the primary sector, the impact of an over-emphasis on numeracy and literacy, and more recently 'key competencies', threatens to undermine past gains through squeezing technology (and other marginalised curriculum areas, such as science and the arts) out of primary school programmes. Teacher understandings of the revised 2007 technology curriculum are also a challenge in the primary sector. As pre-service institutions re-allocate more and more time from specialist learning areas such as technology to numeracy and literacy, primary teachers are graduating with very little understanding of technology and technology education and minimal technology pedagogical content knowledge.

While there are many examples of students from all sectors being involved in innovative and exciting classroom programmes and achieving high levels of technological practice, this is yet to be the 'norm' in all schools across the country. The type of student achievement and teacher practice illustrated by the Beacon Practice case studies, for example, is yet to be exhibited by the 'critical mass' of students and teachers needed to ensure sustainable future development.

New developments and an extension of the sorts of projects established by the GIF-Technology Initiative are planned to address these issues. However, due to the limitations of the GIFTechnology fund focusing on senior secondary technology, concerns in the primary sector are more difficult to address. The biggest challenge in this regard is to secure further funding to focus 
on the primary sector. In keeping with this, plans have been made to attempt to increase the general public's understanding of technology, as well as increase technology-related industries' understanding of, and commitment to, the aims of technology education. Such plans seek to increase the pool of support for technology at all levels of the national curriculum, and in so doing ensure a level of political 'will' to allow the potential of the 2007 technology curriculum to be realised. As many other countries can testify, such political will is key to the health of a new curriculum such as technology and is thus a fundamental issue to address.

In conclusion, we argue that technology has established a space within New Zealand's national curriculum, education research community, and to some extent at least, the lived world of students in compulsory levels of schooling. We look to the future in which this space is not eroded, but rather supported and allowed to evolve further.

\section{NOTES}

1 Maori are the indigenous people of New Zealand and under the Treaty of Waitangi (1840) were guaranteed exclusive and undisturbed rights in terms of preservation of land, fisheries, forest and language. Maori has been an official language in New Zealand (along with English) since 1987.

2 Details of these and other projects funded by the GIF-Technology Initiative can be found at www.techlink.co.nz.

\section{REFERENCES}

Bell, B., Jones, A., \& Carr, M. (1995). The development of the recent national New Zealand Science Curriculum. Studies in Science Education, 26, 73-105.

Burns, J. (1992). Technology-What is it, and what do our students think of it? The NZ Principal, 6(3), 22-25.

Compton, V. J. (2001). Developments in technology education in New Zealand 1993-1995: An analysis of the reflections of key participants. Unpublished doctoral dissertation. University of Waikato, New Zealand.

Compton, V. J. (2004). Technological knowledge: A developing framework for technology education in New Zealand. Briefing paper prepared for the New Zealand Ministry of Education Curriculum Project.

Compton, V. J., \& France, B. (2007a). Redefining technological literacy in New Zealand: From concepts to curriculum constructs. In J. Dakers, W. Dow, \& M. J. de Vries (Eds.), PATT-18, pupils' attitudes towards technology. International conference on design and technology education research book. Teaching and learning technological literacy in the classroom (pp. 260-272). Glasgow, Scotland: Glasgow University.

Compton, V. J., \& France, B. (2007b). Towards a new technological literacy: Curriculum development with a difference. Curriculum Matters, 3, 158-175.

Compton, V. J., \& France, B. (2007c). Exploring the nature of technology: Students' intuitive ideas as a starting point. In J. Dakers, W. Dow, \& M. J. de Vries (Eds.), PATT-18, pupils' attitudes towards technology. International conference on design and technology education research book. Teaching and learning technological literacy in the classroom (pp. 250-259). Glasgow, Scotland: Glasgow University.

Compton, V., \& Harwood, C. (2003). Enhancing technological practice: An assessment framework for technology education in New Zealand. International Journal of Design and Technology Education, 13(1), 1-26.

Compton, V. J., \& Harwood, C. D. (2004). Moving from the one-off: Supporting progression in technology. SET Research Information for Teachers, 1, 23-30.

Compton, V. J., \& Harwood, C. D. (2005). Progression in technology education in New Zealand: Components of practice as a way forward. International Journal of Design and Technology Education, 15(3), 253-287.

Compton, V., \& Jones, A. (1998). Reflecting on teacher development in technology education: Implications for future programmes. International Journal of Technology and Design Education, 8(2), 151-166.

Compton, V. J., \& Jones, A. (2004). The nature of technology. Briefing paper prepared for the New Zealand Ministry of Education Curriculum Project.

Cowie, B., Moreland, J., Jones, A., \& Otrel-Cass, K. (2008). The classroom InSiTE project: Understanding classroom interaction to enhance teaching and learning in science and technology in Years 1-8. Teaching and Learning Research Initiative. Wellington, NZ: New Zealand Council for Educational Research. 
the same. In this context, it is useful to recall excerpts from Mahatma Gandhi's address to teachers at the National Education Conference held under his leadership, at Wardha on 22 October 1937:

What I am going to place before you today is not about a vocation that is going to be imparted alongside education. Now, I wish to say that whatever is taught to children, all of it should be taught necessarily through the medium of a trade or a handicraft. ... Look at takli [spindle] itself, for instance. The lesson of this takli will be the first lesson of our students through which they would be able to learn a substantial part of the history of cotton, Lancashire and the British empire. ... How does this takli work? What is its utility? And what are the strengths that lie within it? Thus the child learns all this in the midst of play. Through this he also acquires some knowledge of mathematics. ... And the beauty is that none of this becomes even a slight burden on his mind. (Gandhi, 1994)

Dilution of such ideas was evident in the conception of the education system even before independence. The following section discusses the form of technical and technology education in school and tertiary levels in post-independent India. It is a commentary on whether and how Mahatma Gandhi's ideas influenced technical education.

\section{OVERVIEW OF TECHNICAL/VOCATIONAL EDUCATION IN POST-INDEPENDENT INDIA}

After India's independence in 1947 , it became a national priority to generate human resources through education to fulfil the future needs of the country, which was envisioned as an industrialising one. This led the Kothari Commission, set up in 1966, to link education to productivity and to propose that science education, work-experience, and vocational education be an integral part of school education. It is within these three subjects that education in and about technology resides rather nebulously in the context of Indian schooling, even today. A brief overview of processes of curricular change involving commissions and their recommendations, and recent national exercises of drawing up curricular frameworks is presented below.

\section{Structure of Education}

Following the recommendations of the Kothari Commission in 1968, a common structure for education was adopted in the whole country (Figure 1). Typically, schooling is for a span of 12 years: 10 years of primary and secondary schooling, and 2 years of senior/higher secondary (referred to as junior college, intermediate, or +2 ). College graduation is normally after 3 years of study. This is popularly denoted as the $10+2+3$ pattern. The National Council of Educational Research and Training (NCERT) is the apex body that formulates the curricular framework and materials for Central schools. State Councils of Educational Research and Training (SCERTs) closely follow NCERT's framework in formulating syllabi and curricular materials for State Board affiliated schools. ${ }^{1}$ At the end of secondary (Grade X) and higher secondary stages (Grade XII), students are assessed through public examinations conducted either by the Central or State Boards. 